\title{
Weatherability of Amorphous Carbon Films Synthesized by Atmospheric-Pressure Plasma-Enhanced Chemical Vapor Deposition
}

\author{
Reiko Inaba, ${ }^{*}$ Eiichi Kishimoto, Akira Shirakura, and Tetsuya Suzuki \\ Graduate School of Science and Technology, Keio University, \\ 3-1-14 Hiyoshi, Yokohama, Kanagawa 223-8522 Japan
}

(Received Novermber 14, 2016; accepted March 21, 2017)

Keywords: weatherability, amorphous carbon films, atmospheric-pressure plasma, chemical vapor deposition, filamentary dielectric barrier discharge

Recently, to prevent the corrosion of concrete structures, a new method of protection has been investigated. Polymer sheets coated with amorphous carbon $(\mathrm{a}-\mathrm{C}: \mathrm{H})$ films to wrap concrete structures is one of the promising solutions. a-C:H films were synthesized by the atmosphericpressure plasma-enhanced chemical vapor deposition method because large-area synthesis is beneficial for huge concrete constructions. The film is intended to be used outdoors; therefore, high weatherability of the film is required. In this study, the goal was to evaluate weatherability and clarify the mechanism of deterioration by light and water. After $100 \mathrm{~h}$ of weathering test, the film thickness decreased because of oxidization and decomposition. The films synthesized by filamentary dielectric barrier discharge have higher weatherability than those synthesized by glow dielectric barrier discharge. In addition, $\mathrm{SiO}: \mathrm{CH} / \mathrm{a}-\mathrm{C}: \mathrm{H}$ multilayer films have higher weatherability than single-layer a-C:H films. The results imply the possibility of the practical application of $\mathrm{a}-\mathrm{C}: \mathrm{H}$ films for the protection of concrete structures.

\section{Introduction}

The durability of concrete structures depends highly on the reduction of the corrosion of concrete and steel caused by the ingress of water and oxygen through cracks or pores on the surface of the concrete. ${ }^{(1)}$ Generally, protective coatings on the concrete surface have been employed to reduce the degradation of the concrete structure. Organic paint is the most used coating, ${ }^{(2)}$ but it needs many layers to satisfy the durability requirements for outdoor use and it takes a long time to complete the process for curing each layer. Therefore, simpler and more rapid concrete protection methods are desired for saving time and cost. Amorphous carbon (a-C:H) films synthesized by the atmospheric-pressure plasma-enhanced chemical vapor deposition (AP-PECVD) method have been attracting attention recently owing to its excellent characteristics, such as high gas barrier, ultraviolet ray screening, and high hardness, which are beneficial for protecting both polymer sheet substrates and concrete structures. ${ }^{(3,4)}$ Moreover, synthesis by AP-PECVD enables low-cost and large area film coating on polymer sheets suitable for cladding large concrete structures ${ }^{(5)}$ Another important factor for protecting concrete is the ability to resist wheathering action, namely, weatherability, since the design service life of concrete structures is several decades. ${ }^{(6)}$

*Corresponding author: e-mail: reiko_05723_naba@yahoo.co.jp

http://dx.doi.org/10.18494/SAM.2017.1503 
However, there is a notable lack of experimental data on the weatherability of a-C:H films. In this research, we aimed at the evaluation and improvement of the weatherability of a-C:H films as a durable protective layer for both polymer sheets, such as polyethyleneterephtalate (PET), and concrete structures. Mori et al. ${ }^{(7)}$ reported that a-C:H films synthesized by AP-PECVD with filamentary dielectric barrier discharge (FDBD) are harder and exhibit characteristics similar to those synthesized by low-pressure PECVD compared to those synthesized by glow dielectric barrier discharge (GDBD). In this paper, we applied these findings to the weathering test of a-C:H films by comparing the discharge modes of FDBD and GDBD.

In addition, in this study, the weatherability of multilayer films made by synthesizing $\mathrm{SiO}: \mathrm{CH}$ films over a-C:H films was investigated, because $\mathrm{SiO}: \mathrm{CH}$ films are reported to have an excellent gas barrier against $\mathrm{O}_{2}{ }^{(8)}$ and are expected to suppress the oxidation of a-C:H films.

\section{Materials and Methods}

\subsection{Film preparation}

A schematic diagram of the AP-PECVD apparatus is shown in Fig. 1. The plasma was sustained between the parallel copper electrodes: the upper electrode, $100 \times 10 \mathrm{~mm}^{2}$ in size, was connected to a high-frequency power supply and covered with a 1-mm-thick alumina dielectric plate, and the lower electrode, $200 \times 300 \mathrm{~mm}^{2}$ in size, was grounded. Agas mixture containing helium (He), argon (Ar), and methane $\left(\mathrm{CH}_{4}\right)$ was introduced between the electrodes to synthesize a- $\mathrm{C}: \mathrm{H}$ films. $\mathrm{CH}_{4}$ is suitable as the raw material because it has only single bonds that reduce the gas phase reaction. The flow rates of $\mathrm{He}, \mathrm{Ar}$, and $\mathrm{CH}_{4}$ were 5,1 , and $400 \mathrm{~mL} / \mathrm{min}$, respectively. The peak voltage of the pulsed power was $6 \mathrm{kV}$, and the pulse duration was $5 \mu \mathrm{s}$. The pulse frequency was fixed at $30 \mathrm{kHz}$. The discharge gap between the substrates and the upper electrode was set at 1 or $4 \mathrm{~mm}$. The discharge at the $1 \mathrm{~mm}$ gap was GDBD, and that at the $4 \mathrm{~mm}$ gap was FDBD.

$\mathrm{SiO}: \mathrm{CH}$ films were synthesized in GDBD mode from the gas mixture containing trimethylsilane [ $\left.\mathrm{SiH}\left(\mathrm{CH}_{3}\right)_{3}\right]$ (TrMS), $\mathrm{O}_{2}$, and $\mathrm{N}_{2}$. TrMS is a gas phase material at room temperature and thus does not require any vaporizing devices. The flow rates of $\mathrm{N}_{2}, \mathrm{O}_{2}$, and TrMS were 20, 500, and 0.05

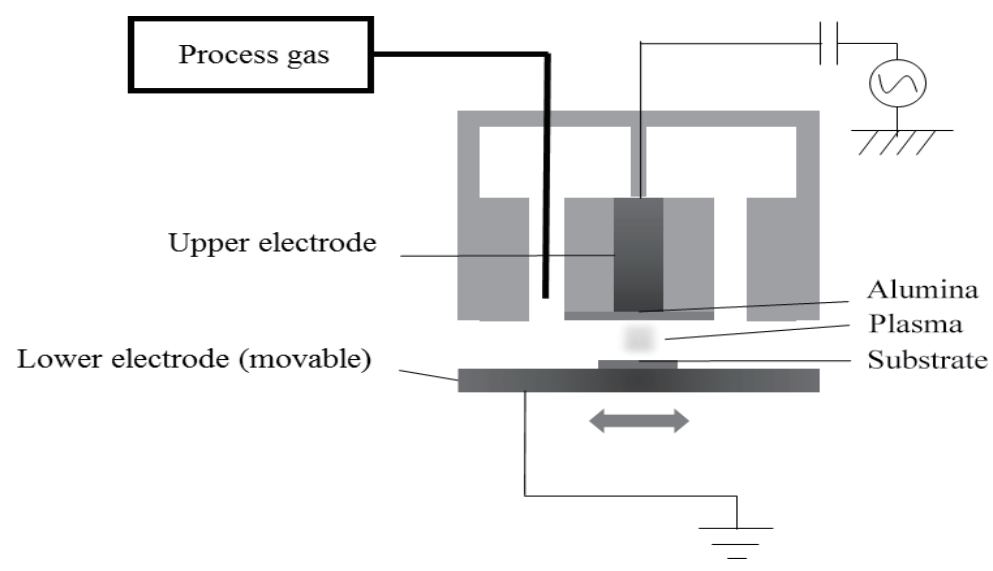

Fig. 1. Schematic view of the AP-PECVD apparatus. 
$\mathrm{mL} / \mathrm{min}$, respectively. The peak voltage of the pulsed power was $6 \mathrm{kV}$, and the pulse duration was $5 \mu \mathrm{s}$. The pulse frequency was fixed at $20 \mathrm{kHz}$. The discharge gap between the substrates and the upper electrode was fixed at $1 \mathrm{~mm}$ to obtain the GDBD mode.

The multilayer films were prepared by synthesizing $\mathrm{SiO}: \mathrm{CH}$ films on a-C:H films. The thickness of the a-C:H films was varied from 100 to $250 \mathrm{~nm}$, and the thickness of the $\mathrm{SiO}: \mathrm{CH}$ films was changed from 50 to $250 \mathrm{~nm}$ by changing the synthesis time.

In this study, the films were synthesized on boron-doped single-crystal silicon ( $\mathrm{Si}$ ) (100) wafers $0.38 \mathrm{~mm}$ thick (SUMCO Corpotation).

\subsection{Film characterization}

The weatherability of the films was evaluated using an accelerated weathering tester with a 390 W $/ \mathrm{m}^{2}$ xenon-arc lamp (Suga Test Instruments Co., Ltd.). The test conditions for the weathering were $100 \mathrm{~h}$ exposure with $12 \mathrm{~min} / 60 \mathrm{~min}$ water spray cycle at the black panel temperature of $63 \pm 2$ ${ }^{\circ} \mathrm{C}$ during radiation on the basis of JIS K 7350-2-1995. Although $3000 \mathrm{~h}$ exposure is required for practical use, in this study we carried out $100 \mathrm{~h}$ exposure to clarify the mechanism of degradation of the films.

The film thickness was measured using a step gauge (Dektak3030, Vesco Instruments, Inc.). The chemical composition was determined by X-ray photoelectron spectroscopy (XPS) (JPS9010TR, JEOL, Inc.), and the bonding configuration was analyzed by Fourier transform infrared spectroscopy (FT-IR) (ALPHA-B, Bruker ASX). The hydrogen composition was inferred by Raman spectroscopy (inVia Raman Microscope, Renishaw, Inc.).

\section{Results}

\subsection{Comparison between GDBD and FDBD}

Figure 2 shows the thicknesses of the a-C:H films before and after the weathering test. The films synthesized by GDBD disappeared after the test. On the other hand, those synthesized by

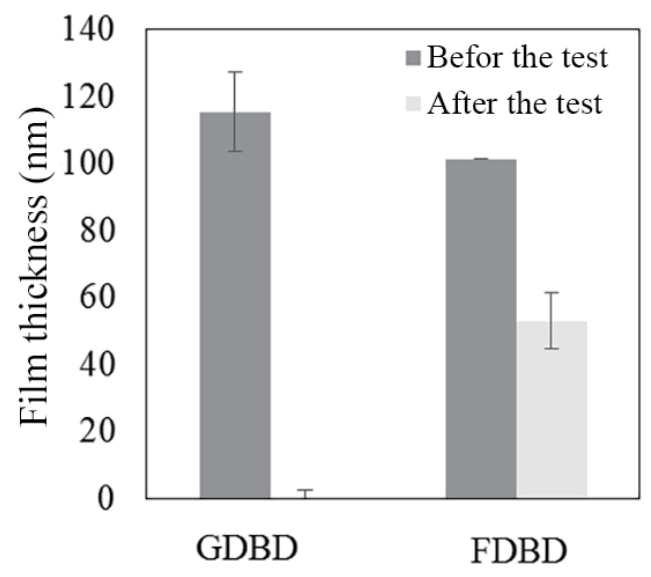

Fig. 2. Thickness of a-C:H films before and after the weathering test. 
FDBD remained, although the thicknesses of the films decreased uniformly from 101.3 to $53.0 \mathrm{~nm}$.

Table 1 shows the chemical composition of a-C:H films before and after the weathering test. The amount of oxygen $(\mathrm{O})$ in the remaining film synthesized by FDBD increased after the weathering test. This result suggests that the surfaces of the films were oxidized by $\mathrm{O}_{2}$ in air. Figure 3 shows the $\mathrm{C}$ 1s spectra of the films synthesized by FDBD before and after the test. The main peak in the spectra has been charge corrected to $284.8 \mathrm{eV}$. These spectra show that the peaks due to $\mathrm{C}-\mathrm{O}(1.3-1.7 \mathrm{eV}$ above the main peak) and $\mathrm{C}-\mathrm{OOH}(4.0-4.5 \mathrm{eV}$ above the main peak) increased after the test. ${ }^{(9)}$ Figure 4 shows the IR spectra of the a-C:H films. For the films synthesized by FDBD, the peak due to $\mathrm{OH}$ at about $3400 \mathrm{~cm}^{-1(10,11)}$ increased after the test. This result indicates that the amount of $\mathrm{OH}$ increased after the weathering test. After the weathering test, the amount of $\mathrm{OH}$ in the films remained increased. This result indicates that the surface was oxidized by $\mathrm{O}_{2}$ in air. ${ }^{(13,14)}$

It is said that $\mathrm{H}$ in water acts as a catalyst to oxidize the surface. ${ }^{(15)}$ The intermittent water showering during the weathering test is considered to accelerate the oxidation. ${ }^{(15)}$ Therefore, the amount of $\mathrm{O}$ at the surface of the films synthesized by FDBD increased after the test. After oxidation, the bonds of a-C:H were decomposed and dispersed. Therefore, the film thickness decreased after the weathering test.

The films synthesized by FDBD have a better weatherability than those synthesized by GDBD. It is reported that the films synthesized by FDBD have less $\mathrm{H}$ than those synthesized by GDBD. ${ }^{(7)}$ Figure 5 shows the Raman spectra of the films synthesized by FDBD and GDBD. Adamopoulos

Table 1

Chemical composition of a-C:H films before and after the weathering test.

\begin{tabular}{ccccccc}
\hline & \multicolumn{2}{c}{ Before } & & \multicolumn{2}{c}{ After } \\
\cline { 2 - 3 } \cline { 6 - 7 } GDBD & C (at.\%) & C (at.\%) & & C (at.\%) & C (at.\%) \\
\cline { 6 - 7 } & 91.3 & 8.7 & & \multicolumn{2}{c}{ No data } \\
\multirow{2}{*}{ FDBD } & 97.3 & 2.7 & & \multicolumn{2}{c}{27.1} \\
& 86 & 14 & & 72.9 & 2.9 \\
\hline
\end{tabular}

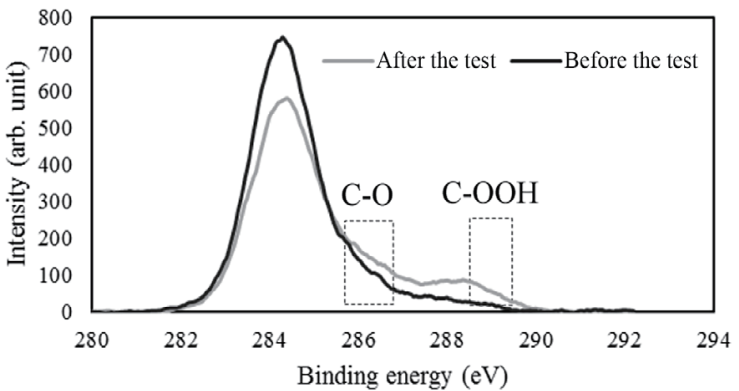

Fig. 3. XPS spectra of a-C:H films synthesized by FDBD before and after the weathering test.

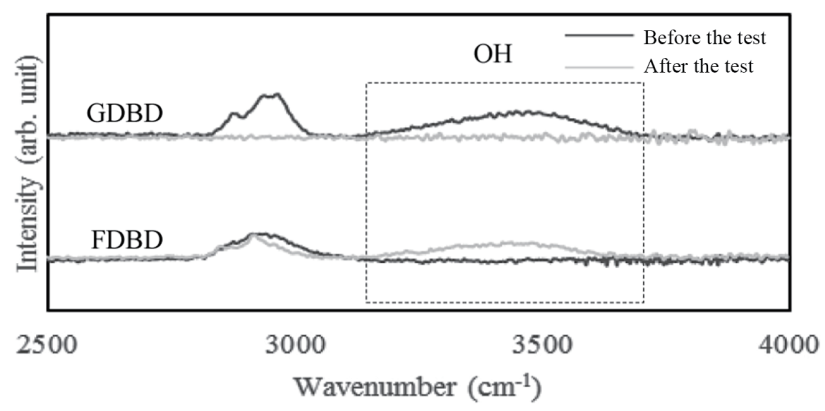

Fig. 4. IR spectra of a-C:H films before and after the weathering test. 


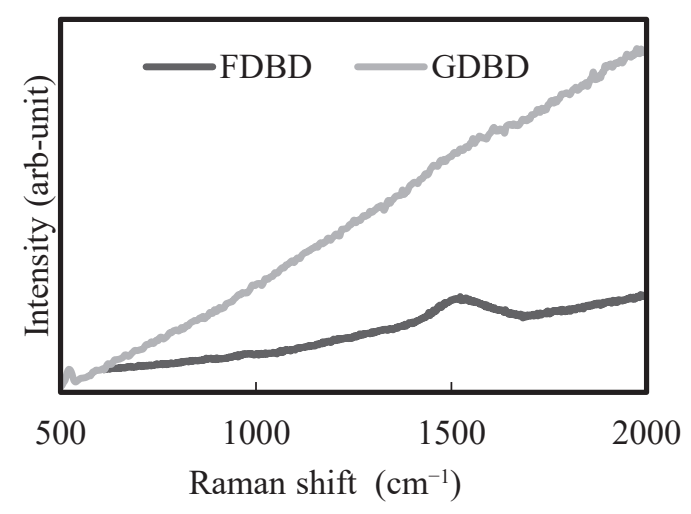

Fig. 5. Raman spectra of a-C:H films before and after the weathering test.

et al. have reported that the background slope is a sensitive function of the hydrogen content of the film. ${ }^{(12)}$ This result indicates that the films synthesized by FDBD have less $H$ than those synthesized by GDBD because the slope of the spectra of the films synthesized by GDBD is larger than that of the films synthesized by FDBD. Since oxidation is more likely to occur at $\mathrm{C}-\mathrm{H}$ bonds, ${ }^{(13)}$ the films synthesized by FDBD exhibited higher resistance to oxidation owing to less content of $\mathrm{C}-\mathrm{H}$ bonds. It is said that the oxidation of hydrocarbons begins at $\mathrm{R}-\mathrm{H}$ bonds, ${ }^{(16)}$ so that the films synthesized by FDBD are less likely to be oxidized.

\subsection{SiO:CH/a-C:H multilayer films}

Figure 6 shows the thicknesses of the multilayer films before and after the weathering test as a function of the thickness of $\mathrm{SiO}: \mathrm{CH}$ films. The reduction in thickness of the multilayer films was larger with 150-nm-thick a-C:H films than with 250-nm-thick a-C:H films. To determine bonding configuration before and after the weathering test, FT-IR measurements were carried out. Figure 7 shows the IR spectra of the multilayer films before and after the weathering test as a function of thickness of SiO:CH films. The main band is the Si-O stretch at $1100-1000 \mathrm{~cm}^{-1}$. ${ }^{(17)}$ For the multilayer films with 150 -nm-thick a-C:H films, the $\mathrm{Si}-\mathrm{O}$ stretching band disappeared after the weathering test. In contrast, for the multilayer films with 250-nm-thick a-C:H films, the peak remained after the weathering test. This result indicates that $\mathrm{SiO}: \mathrm{CH}$ films on 150 -nm-thick a-C:H films disappeared, but $\mathrm{SiO}: \mathrm{CH}$ films on 250-nm-thick a-C:H films remained after the weathering test.

These results are considered to be caused by differences in thermal expansion. During the weathering test, $12 \mathrm{~min}$ of water spraying was conducted every hour, which induces a decrease in panel temperature of about $20 \mathrm{~K}$ and thermal expansion and contraction cycles of the films and substrates. The linear thermal expansion of single-crystal $\mathrm{Si}$ is $3.57 \times 10^{-6} / \mathrm{K},{ }^{(18)}$ and that of $\mathrm{SiO}: \mathrm{CH}$ and a-C:H films is $5.4 \times 10^{-7} / \mathrm{K}^{(19)}$ and $2.26 \times 10^{-6} / \mathrm{K},{ }^{(20)}$ respectively. The thermal expansion of a-C:H films is an intermediate value between those of $\mathrm{Si}$ and $\mathrm{SiO}: \mathrm{CH}$ films, so that a-C:H films worked as a buffer. The 250-nm-thick a-C:H films were sufficiently thick to ease the transmission of the modification of $\mathrm{Si}$ substrates to $\mathrm{SiO}: \mathrm{CH}$ films. On the other hand, 150-nmthick a-C:H films were not sufficiently thick to ease the deformation and generated a higher 


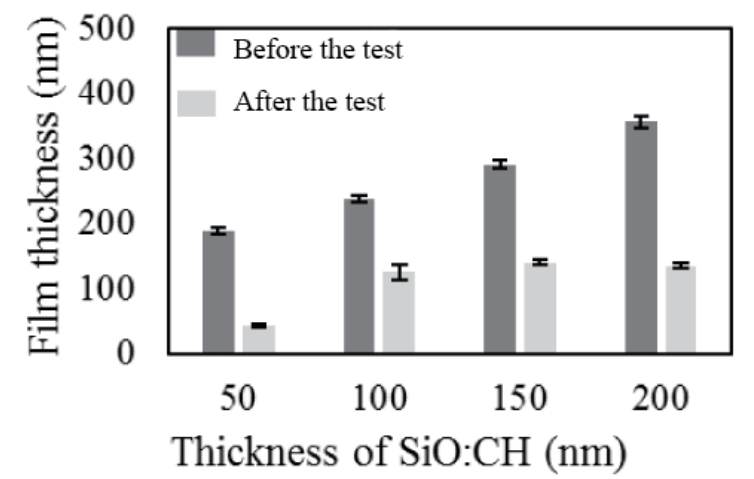

(a)

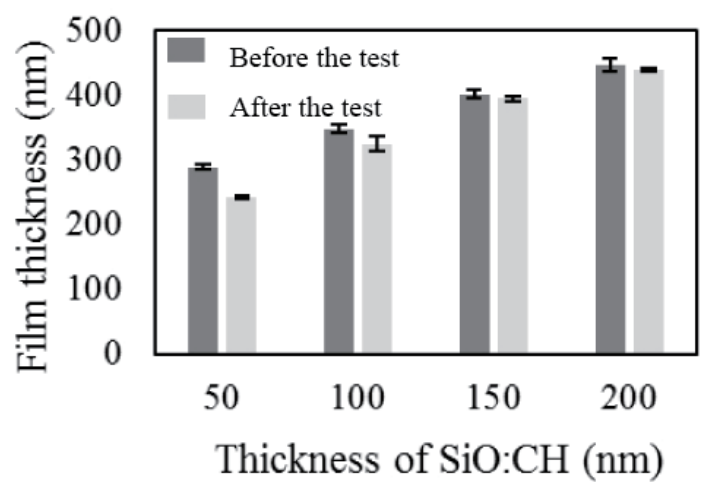

(b)

Fig. 6. Thickness of the multilayer films with (a) 150- and (b) 250-nm-thick a-C:H films as a function of thickness of $\mathrm{SiO}: \mathrm{CH}$ films before and after the weatherability test.

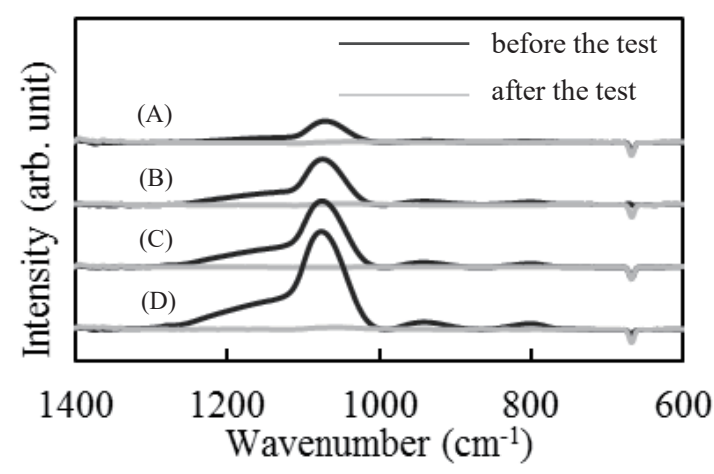

(a)

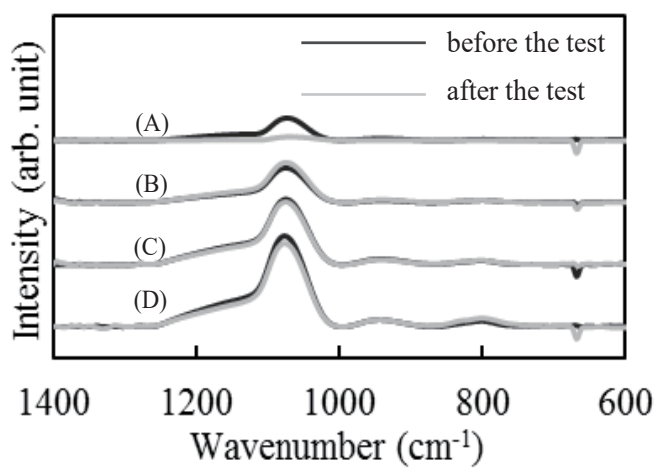

(b)

Fig. 7. IR spectra of laminated films with (a) 150-nm-thick and (b) 250-nm-thick a-C:H films as a function of thickness of (A) 50-, (B) 100-, (C) 150-, and (D) 200-nm-thick SiO:CH films before and after the weathering test.

interlayer shear stress between the a-C:H and $\mathrm{SiO}: \mathrm{CH}$ films. It is probable that the exfoliation of $\mathrm{SiO}: \mathrm{CH}$ films on 150-nm-thick a-C:H films occurred owing to repeated interlayer stress.

The thickness of the SiO:CH films on the 250-nm thick a-C:H films decreased after the weathering test because $\mathrm{Si}-\mathrm{C}$ and $\mathrm{Si}-\mathrm{H}$ bonds were cleaved by exposure to ultraviolet light. A xenon arc lamp hardly emits a wavelength under $300 \mathrm{~nm}$, which is equivalent to $400 \mathrm{~kJ} / \mathrm{mol}$. The bond dissociation energies of $\mathrm{Si}-\mathrm{C}, \mathrm{Si}-\mathrm{H}$, and $\mathrm{Si}-\mathrm{O}$ are $337.4,318$, and $425.6 \mathrm{~kJ} / \mathrm{mol}$, respectively, ${ }^{(21,22)}$ and $\mathrm{Si}-\mathrm{C}$ and $\mathrm{Si}-\mathrm{H}$ bonds were cleaved by the ultraviolet light from the xenon arc lamp but the $\mathrm{Si}-\mathrm{O}$ bonds remained unbroken.

The SiO:CH/a-C:H multilayer films had a better weatherability than a-C:H films. Silica is reported to have an excellent gas barrier to $\mathrm{O}_{2}{ }^{\left({ }^{8}\right)}$ and the $\mathrm{O}_{2}$ molecules did not reach the a-C:H films. The degradation of a-C:H films is mainly caused by oxidation, so that the decrease in the thickness of a-C:H films was less likely to occur in multilayer films than in single-layer films. 


\section{Conclusions}

It was indicated that, after the weathering test, the film thickness decreased because of oxidization and decomposition. The films synthesized by GDBD disappeared after the test. On the other hand, those synthesized by FDBD remained. The films synthesized by FDBD have excellent weatherability compared to those synthesized by GDBD.

The SiO:CH/a-C:H multilayer films had a better weatherability than a-C:H films. This result implies the possibility of applying the SiO:CH/a-C:H multilayer films to practical use for the protection of concrete structures.

\section{Acknowledgments}

We are most grateful to R. Matsuo and T. Watanabe (Kanagawa Industrial Technology Center) for their assistance with the experiments.

\section{References}

1 J. B. Aguiter, A. Camoes, and P. M. Moreira: J. Adv. Concr. Technol. 6 (2008) 243.

2 R. Selvaraj, M. Selvaraj, and S. V. K. Lyer: Prog. Org. Coat. 64 (2009) 454.

3 G. A. Abbas, S. S. Roy, P. Papakonstantinou, and J. A. McLaughlin: Carbon 43 (2005) 303.

4 S. J. Bull: Diam. Relat. Mater. 4 (1995) 827.

5 M. Noborisaka, T. Hirako, A. Shirakura, T. Watanabe, M. Morikawa, M. Seki, and T. Suzuki: Jpn. J. Appl. Phys. 51 (2012) 090117.

6 D. C. Park: Constr. Build. Mater. 22 (2008) 2260.

7 T. Mori, Y. Futagami, E. Kishimoto, A. Shirakura, and T. Suzuki: J. Vac. Sci. Technol. A 33 (2015) 060607.

8 T. N. Chen, D. S. Wuu, C. C. Chiang, Y. P. Chen, and R. H. Horng: J. Electrochem. Soc. 153 (2006) F244.

9 S. Yumitori: J. Mater. Sci. 35 (2000) 139-146.

10 Y. Marechal, and H. Chanzy: J. Mol. Struct. 523 (2000) 183.

11 B. Hinterstoisser, M. Akerholm, and L. Salmen: Carbohyd. Res. 334 (2001) 27.

12 G. Adamopoulos, J. Robertson, N. A. Morrison, and C. Godet: J. Appl. Phys. 96 (2004) 6348.

13 K. Sato: Color Mater.1 41 (1968) 126 (in Japanese).

14 H. W. Gibson and J. M. Pochan: Macromolecules 15 (1982) 242.

15 T. Matsuda and F. Kurihara: Jpn. J. Polym. Sci. 22 (1965) 243 (in Japanese).

16 R. C. Chambers and C. H. Hill: Inorg. Chem. 28 (1989) 2509.

17 P. G. Pai, S. S. Chao, Y. Takagi, and G. Lucovsky: J. Vac. Sci. Tech. A 4 (1986) 689.

18 W. M. Yim and R. J. Paff: J. Appl. Phys. 45 (1974) 1456.

19 S. Miyake, Y. Kinomura, and T. Suzuki: Inorg. Mater. 5 (1998) 612 (in Japanese).

20 I. A. Blech and P. Wood: J. Vac. Sci. Tech. A 11 (1993) 728.

21 M. K. Beyer: J. Chem. Phys. 112 (2000) 7307.

22 S. Tatsuya, Y. Matsuki, M. Furusawa, T. Aoki, I. Yudasaka, H. Tanaka, H. Iwasawa, D. Wang, M. Miyasaka, and Y. Takeuchi: Nature 440 (2006) 783. 